УДК 536.24: 697.1

\title{
НЕКОТОРЫЕ ПУТИ СНИЖЕНИЯ ЭНЕРГОЗАТРАТ ЗДАНИЙ ПУТЕМ РЕГУЛИРОВАНИЯ ТЕПЛОПОТРЕБЛЕНИЯ
}

\author{
Круковский П.Г., Д-р техн. наук, Тадля О.Ю., канд. техн. наук, Дейнеко А. И., Скляренко Д. И. \\ Институт технической теплофизики НАН Украины, ул. Желябова, 2а, Киев-57, 03057, Украина
}

\begin{abstract}
Проведено аналіз методів підвищення енергоефективності будівель за допомогою регулювання теплоспоживання різними пристроями (включаючи індивідуальні теплові пункти) без- і з урахуванням контролю температури повітря в приміщеннях (зворотного зв'язку). Особливу увагу приділяється методу економії енерговитрат за рахунок зниження температури повітря в періоди відсутності людей. На прикладі аналізу теплового стану старого адміністративного будинку с низькою енергоефективністю показані шляхи зниження енерговитрат до $4 \%$ при централізованому теплопостачанні.
\end{abstract}

Проведен анализ методов повышения энергоэффективности зданий посредством регулирования теплопотребления различными устройствами (включая индивидуальные тепловые пункты) без- и с учетом контроля температуры воздуха в помещениях (обратной связи). Особое внимание уделяется методу экономии энергозатрат за счет снижения температуры воздуха в периоды отсутствия людей. На примере анализа теплового состояния старого административного здания с низкой энергоэффективностью показаны пути снижения энергозатрат до 4 \% при централизованном теплоснабжении.
Carried the analysis methods for increasing energy efficiency in buildings by controlling heat consumption of various devices (including individual heating units) unand taking into account the control of the room temperature (feedback). Special attention is given to the saving energy method by reducing the air temperature in the periods of people absence. On the example of the low energy old administrative building's thermal state shown the ways energy consumption reducing to $4 \%$ in the district heating.

Бібл. 8, рис. 3.

Ключевые слова: экономия энергии на отопление здания, управление системой отопления, индивидуальный тепловой пункт, динамическая тепловая модель здания, эксперимент в здании, регулирование температуры воздуха в здании.

Среди методов снижения энергопотребления систем отопления зданий наиболее дешёвыми являются методы контроля и оптимального регулирования теплопотребления зданий с помощью существующей системы управления отоплением. В старых зданиях часто заменяют существующие элеваторы на индивидуальные тепловые пункты (ИТП) [1], что позволяет более точно регулировать и снижать теплопотребление зданий, например, путем устранения «перетопов» в теплое время зимы, но часто не позволяет устранить «недотопы» в холодное время зимы вследствие недостаточной температуры теплоносителя в сети, изза чего в зданиях снижается температура воздуха.

Регулирующие приборы осуществляют ре- гулирование температуры воздуха в помещении как по схеме с учетом, так и по схеме без учета обратной связи. Однако во многих схемах заданная температура в помещениях поддерживается за счет подбираемых (в основном вручную) графиков изменения температуры теплоносителя в зависимости от времени суток на основе, так называемой, базовой кривой отопления здания,зависимости расхода сетевой воды или температуры подающей воды в систему отопления здания от температуры окружающей среды.

Определённую экономию можно также получить за счет максимального снижения температуры воздуха в здании во время отсутствия людей. Суть способа состоит в том, что во вре- 
мя отсутствия людей система отопления снижает свою мощность, и температура воздуха в помещении также снижается до определенного значения экономной температуры, при которой не происходит конденсация влаги на внутренней поверхности наружных ограждениях здания. Затем в некоторый момент времени (в [2,3] называемый оптимальным временем включения) система отопления включается для прогрева воздуха до заданной пользователем температуры к моменту прихода людей в помещения. Алгоритм определения оптимального времени включения, основанный на использовании тепловой модели помещения, детально описан в [2].

В литературе имеются некоторые примеры применения этого метода. Так, авторы работы [4] предлагают алгоритм управления тепловым режимом помещений, основанный либо на минимуме теплопотребления, либо на минимуме оплаты за электроэнергию (использование льготного ночного тарифа). Приведенное в [4] значение экономии энергии составляет $4 . .5 \%$ для обоих алгоритмов. В [5] указано что, чем ниже мощность системы отопления в период остывания и чем выше мощность системы отопления в период нагрева, тем эффективней будет регулирование и больше величина экономии тепловой энергии. По результатам расчетов приводится значения экономии 6,4 \% (при мощности «нагрева» большей, чем стационарная на $40 \%$ ).

В данной работе на примере административного здания с низкой энергоэффективностью рассматриваются ряд путей снижения энергозатрат посредством введения обратной связи и улучшения суточного регулирования теплопотребления с помощью существующего в здании ИТП и тепловой модели здания.

Рассмотрим четырехэтажное административное здание Института технической теплофизики (ИТТФ) старой постройки (60-ые годы XX века) в г. Киеве, которое имеет 130 помещений. Здание имеет самый низкий класс энергоэффективности - F [6]. В здании имеется ИТП с погодозависимым регулированием без обратной связи между зданием и ИТП. Управление ИТП осуществляется положением автоматической задвижки на входящем трубопроводе теплосети, которое обеспечивает необходимую температуру воды из теплосети согласно базовой кривой отопления. Для данного здания управление ИТП осуществляется неэффективно, поскольку не учитываются изменение количества людей, величины бытовых тепловыделений в течении суток, наличие ветра и влияния солнечной радиации.

\section{Анализ возможных путей снижения энерго- затрат проводилось по следующей схеме:}

1. Проведение экспериментальных измерений температур в различных помещениях здания;

2. Построение и настройка по экспериментальным данным тепловой модели здания ИТТФ;

3. Анализ возможного снижения энергозатрат путем уточнения базовой кривой ИТП;

4. Анализ и прогнозирования других способов снижения энергозатрат, включая введение обратной связи и использования способа экономии в периоды отсутствия людей.

Экспериментальные измерения. Измерялись температуры окружающей среды и воздуха в здании в пяти типичных помещениях. В ИТП измерялись количество теплоты для отопления здания, температуры сетевой воды, подачи и обратки в систему отопления здания и ее расход.

Построение тепловой модели ГК. Модель выбиралась простой и достаточно информативной для проведения анализа, поскольку только при наличии модели всего здания можно достичь наиболее эффективного регулирования теплового режима этого здания. Модель учитывала совместное тепловое состояние конструкций здания, воздуха в нем, системы отопления и регулирующего устройства.

На рис. 1 приведена выбранная схема тепловой модели здания с системой отопления и ИТП. В модели присутствуют четыре узла, - три расчетных (воздух в здании, система отопления и ограждающие конструкции) и один задаваемый - температура окружающей среды. Связь между узлами осуществляется с помощью эффективных (учитывающих кондуктивный, конвективный и лучистый теплообмен) коэффициентов теплопередачи. Расчетные узлы учитывают инерционные 
свойства (полные теплоемкости) структурных элементов здания, воздуха и системы отопления. Три термических сопротивления и три полные теплоемкости идентифицировались по экспериментальным измерениям средней температуры воздуха в 5-ти помещениях и средней температуре системы отопления с помощью алгоритмов, описанных в [2,3].

Результаты расчетов показывают, что модель в динамическом режиме достаточно хорошо описывает изменение температуры воздуха в здании. Температура воздуха качественно по- вторяет изменения температуры окружающей среды с опозданием, вызванным инерцией здания (рис. 2. кривые 2 и 3). По результатам, представленным на рис. 2 видно, что существующий алгоритм регулирования, реализованный в ИТП, работает плохо, поскольку имеют место как «перетоп» до $1^{\circ} \mathrm{C}$, так и недогрев помещений до $1,5^{\circ} \mathrm{C}$.

Разработанная модель использовалась для анализа и прогнозирования эффективности следующих различных способов снижения энергозатрат в здании.

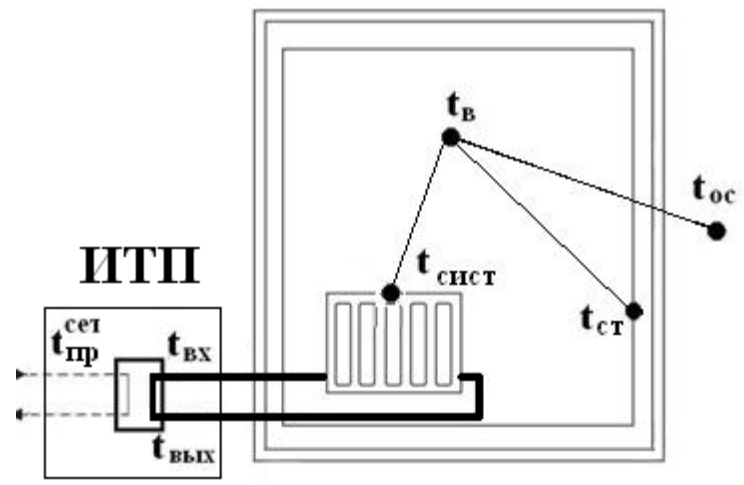

Рис. 1. Схема рассматриваемого здания с указанием узлов и тепловых связей модели.

Уточнение базовой кривой ИТП. Для уточнения базовой кривой в стандартной методике [7] использовались найденные по результатам идентификации значения параметров. Предлагаемая кривая лежит на $4{ }^{\circ} \mathrm{C}$ выше при температуре окружающей среды равной $-10{ }^{\circ} \mathrm{C}$. В большинстве помещений здания по результатам экспериментальных исследований температура воздуха не поддерживалась на заданном уровне $18{ }^{\circ} \mathrm{C}$ (см. рис. 2). Экономия энергии за период эксперимента при уточнении базовой кривой отопления составила - 3,4 \%. Отрицательная величина экономии связана с тем, что существующая базовая кривая не поддерживает заданный уровень температуры воздуха в здании на уровне $18^{\circ} \mathrm{C}$.

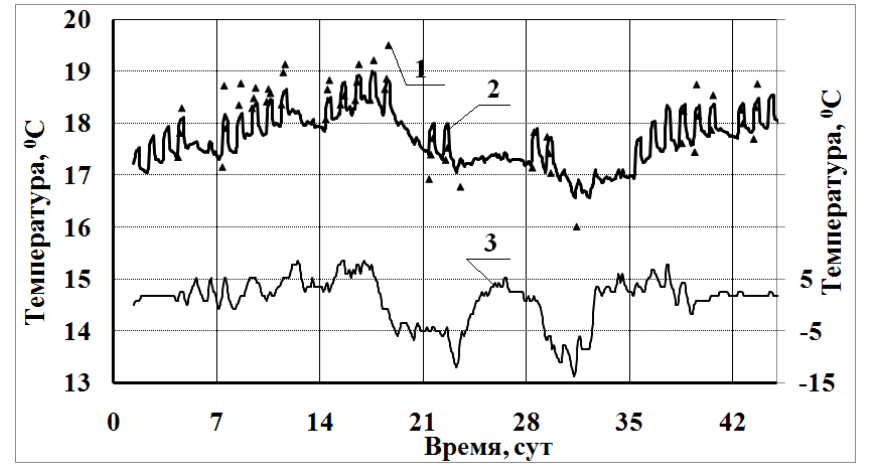

Рис. 2. Зависимость температуры воздуха в здании от времени. 1 - эксперимент, 2 - расчетные температуры, 3 - температура окружающей среды (по правой икале). 
Введение обратной связи и алгоритма управления временем включения системы отопления $\boldsymbol{\tau}^{*}$. Для здания введение обратной связи и алгоритма управления временем включения системы отопления позволяет получить экономию 3,7 \% и обеспечить более комфортные условия для людей. Здание обладает большой инерционностью, - за один рабочий день с 9 до 18 часов температура воздуха всего два раза повышается, а потом снижается в пределах заданного диапазона (рис. 3). Колебания температуры воздуха вызваны также наличием бытовых тепловыделений в дневное время, которые в ночное время отсутствуют.

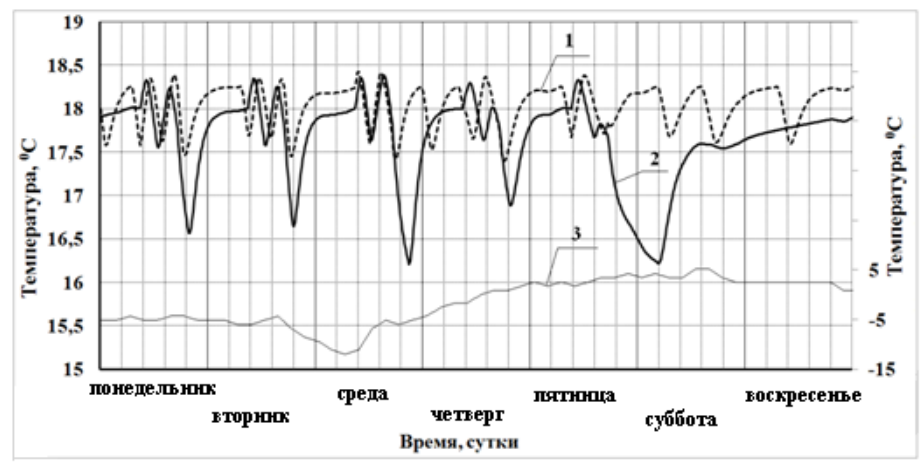

\section{Рис. 3. Зависимость температуры воздуха в помещениях $(1,2)$ и окружсающей среды (3) от времени. 1 - поддержание температуры воздуха в заданном интервале, 2 - режим снижения температуры воздуха.}

Расчеты показывают, что здание имеет возможность потреблять тепловую мощность от теплосети на величину, большую, чем его теплопотери (так называемый - запас мощности 3М) на $6 . . .8 \%$. Этим и объясняется маленькая величина экономии тепловой энергии при периодическом снижении температуры воздуха в помещениях в нерабочее время, при больших значениях 3М экономия будет больше [8]. При низких значениях температур окружающей среды (ниже $-10{ }^{\circ} \mathrm{C}$ ) данный способ экономии энергии нельзя применять, поскольку теплосеть дает недостаточный 3М.

Таким образом, снижение энергозатрат путем улучшения алгоритмов управления работы ИТП относится к малозатратным мероприятиям, поскольку его использование не нуждается в существенных капитальных и эксплуатационных затратах.

\section{Выводы}

1. Возможности регулирования теплопотребления зданий недостаточно используются для повышения энергоэффективности существующих зданий особенно старой постройки с устаревшими системами отопления. Для его эффективного использования необходимо наличие контроля температуры воздуха в здании различными устройствами и введения обратной связи между помещениями здания и его ИТП.

2. Для определения оптимального алгоритма регулирования необходимо наличие модели теплового состояния здания, которая может быть построена на основе кратковременных (1...3 недели) измерений температур воздуха, прямой и обратной температуры воды в теплосети, расхода воды в теплосети и желательно бытовых тепловыделений.

3. На примере анализа теплового состояния административного здания с низкой энергоэффективностью показаны пути снижения энергозатрат до 4 \% при централизованном теплоснабжении.

Авторы выражают благодарность сотрудникам ИТТФ Бабаку В.П. и Назаренко О.А. за помошь в получении экспериментальных данных.

\section{ЛИТЕРАТУРА}

1. СП 41-101-95 Своды правил по проектированию и строительству. Проектирование тепловых пунктов.

2. Круковский П.Г., Тадля О.Ю., Метель М.А., 
Скляренко Д.И. Методическое обеспечение способа экономии энергии за счет периодического снижения температуры воздуха в помещении // Промышленная теплотехника. - 2014. - т. 36, №1. - c. 50-58.

3. Круковский П.Г., Скляренко Д.И., Тадля О.Ю., Метель М.А. Определение параметров теплопотерь помещений при нестационарном тепловом режиме// Промышленная теплотехника. - 2013. т. 35, №6. - c. 47-56.

4. Berthou T., Stabat R., Salvazet R., Marchio D. Optimal control for building heating: an elementary school case study // Proceedings of BS2013: 13th Conference of International Building Performance Simulation Association, Chambéry, France. - August 26- 28. - P. 1944-1951.
5. Панферов В.И., Анисимова Е.Ю., Нагорная А.Н. Об оптимальном управлении тепловым режимом здания // Вестник ЮУрГУ, Серия: Энергетика. - 2007. - №20. - с. 3-9.

6. ДБН В.2.6-31:2006 Конструкції будинків i споруд. Теплова ізоляція будівель.

7. Наладка и эксплуатация водяных тепловых сетей: Справочник/В. И. Манюк, Я. И. Каплинский и др.-3-е изд., перераб. и доп.- М.: Стройиздат, 1988.-432 с.

8. Круковский П.Г., Тадля О.Ю., Метель М.А. Влияние запаса мощности системы отопления на эффективность способа экономии энергии за счет снижения температуры воздуха в помещении// Промышленная теплотехника. - 2009. - № 2. - C. 76-82. 


\section{SOME WAYS TO REDUCED ENERGY COSTS BUILDINGS BY REGULATING HEAT CONSUMPTION}

\section{Krukovsky P. G., Tadlia O.Y., Deineko A. I., Sklyarenko D.I.}

Institute of Engineering Thermophysics of the National Academy of Sciences of Ukraine, vul. Zhelyabova, 2, a, Kyiv-57, 03057, Ukraine

Key words: saving energy for heating buildings, control heating, individual heat point, dynamic building thermal model, building experiment, building air temperature control.

Carried the analysis methods for increasing energy efficiency in buildings by controlling heat consumption of various devices (including individual heating units) un- and taking into account the control of the room temperature (feedback).

Special attention is given to the saving energy method by reducing the room air temperature in the people absence periods. This low-costly way to save energy is not enough currently in use due to the absence of optimal control algorithms ITP. Although the potential of this method can reach $15 \ldots 20 \%$.

It is shown that for effective regulation to save energy, you must have control of the room air temperature of the various devices (including individual heating units) and the introduction of a feedback between the room building and ITP.

On the example of the low energy old administrative building's thermal state shown the ways energy consumption reducing to $4 \%$ in the district heating.
References 8, fig. 3.

1. SP 41-101-95 Practice Guidelines for design and construction. Design of heat points.

2. Krukovsky P. G., Tadlia O.Y., Metel M.A., Sklyarenko D.I. Methodical maintenance saving energy by periodic reduce room air temperature // Prom. teplotekhnika. - 2013. - № 6. - P. 47 -56. (Rus).

3. Krukovsky P.G., Tadlia O.Y., Metel M.A., Sklyarenko D.I. Heat losses room's parameters determination under transient thermal state // Prom. teplotekhnika. - 2014. - №1. - P. 50-58. (Rus).

4. Berthou T., Stabat R., Salvazet R., Marchio D. Optimal control for building heating: an elementary school case study // Proceedings of BS2013: 13th Conference of International Building Performance Simulation Association, Chambéry, France. - August 26- 28. - P. 1944-1951.

5. Panferov V.I., Anisimova E.U., Nagornaya A.N. Optimal control of thermal regime of the building // Vestnik SU-SU, Series: Energy. - 2007. - №20. - P. 3-9.

6. DBN V.2.6-31: 2006 Construction of buildings and structures. Thermal insulation buildings.

7. Setting up and operation of the water heating networks: Manual / B. I. Manyuk, YI Kaplinsky and others-3rd ed., Rev. and dop.- M .: Stroyizdat, 1988.$432 \mathrm{p}$.

8. Krukovsky P.G., Tadlia O.Y., Metel M.A. Power reserve heating system influence on the effective way to save energy by reducing the air room temperature // Prom. teplotekhnika. - 2009. № 2. - P. 76-82. (Rus). 